their peculiar hieroglyphic inscriptions, have recently been republished in a handy form in Dr. A. E. Cowley's Schweich Lectures for 1918. The Hittite hieroglyphs not seldom appear upon the seals, and the whole facies of their designs demonstrably belongs to the same art as the greater monuments associated with the Hittites. They show also, as was to be expected, many points of contact with Minoan glyptic art on the one side and with Babylonian on the other, nor in the later examples are Egyptian influences indiscernible. The existence, which is now certain, of a Semitic Babylonian population in the cisTaurus region (the district of Argaeus and Caesarea Mazaca, the modern Kaisariyeh), as early as the time of the Dynasty of Ur 'of the Chaldees,' about 2,500 B.c., which was later extinguished, no doubt by the Hittites, gives us the reason of the strong Babylonian elements in Hittite glyptic. Mr. Hogarth also makes several interesting references to the hypothetical Minoan-Hittite Mischkunst of the Eastern Keftians of Cilicia, where, in all probability, the land of Alashiya so often mentioned in the Egyptian inscriptions and in the cuneiform Tell-el-Amarna letters is to be placed. And this mixed art is closely connected with the early art of Cyprus, where from the fifteenth or fourteenth century B.c. onwards we see occidental and oriental artistic elements always contending for the mastery. One speaks of this presumably Cilician art as hypothetical, because no excavations have as yet been carried out in Cilicia which would give us archaeological authority for so describing it. There can, however, be little doubt that, if ever in the future excavations are made, presumably now under French auspices, in Cilicia, the strata of the later Bronze Age will yield the characteristic seals, ivory carvings, and other objects, hitherto found chiefly in Syria, in Cyprus or in Egypt, which are on many cogent grounds to be assigned to Cilicia as their place of origin. To distinguish the products of this mixed art from those of the fine Hittite style is a study of the greatest interest, and it is to be hoped that Mr. Hogarth will later on publish a study of the works of the presumed Cilician style, to which many of the supposed Minoan objects discovered in Cyprus and in Egypt should in reality belong. So far as the genuinely Hittite art is concerned, he has in this commentary on the seals written a most useful study of its characteristics as revealed in the domain of smaller objects, and his chapter on the 'Dating and Local Origin' of the seals furnishes conclusive arguments for the dating of the larger monuments, which will commend themselves to all who understand matters of artistic style, and do not need the authority of an inscription to tell them the approximate date of an ancient work of art.

H. $\mathrm{H}$.

\title{
L'Hellénisme primitif de la Macédoine prouvé par la Numismatique et l'Or du Pangée. Par J. N. Svoronos. Pp. 262, with 19 Plates and Map, no Index. Paris: Leroux; Athens : Eleftheroudakis. 1919.
}

One of the chief faults of this book is apparent in its title. If the author had realised that to demonstrate the Hellenic character of the population inhabiting North-Eastern Macedonia two thousand years ago does not assist the solution of present-day political problems he might have produced a more scientific work. This is not to say that the book is mere propaganda ; there is too much special pleading; conclusions based on far tou slender grounds are continually used as springboards for further plunges; but if the reader will persevere to the end of the book in spite of its haphazard arrangement and too numerous wrong references he will find that his ideas have had a thorough shake up and that several attributions which he had hitherto accepted without question are none too well grounded.

The work falls into two parts: in the first (of which the substance has already appeared in the Journal International d'Ascheologie Numismutique for 1913), the author takes the series of archaic silver coins recognised by numismatists generally as being of Thraco-Macedonian origin--some of them inscribed with the names of more or less 
known tribes-adds to them several more on grounds of type, fabric or symbol, and attempts to assign them to various Paeonian tribes or Hellenic cities whose position he proceeds to locate in the districts between the Axius and the Nestus. In the second part he sets himself to identify the gold coinage which he thinks must have been struck in these same districts in view of the rich gold mines which they contain, and this leads him to transfer thither much of the primitive electrum coinage hitherto given to Ionia and notably the so-called Ionian-revolt issues.

In the first part the symbols on which $\mathbf{M}$. Svoronos relies as evidence of Paeonian origin are two: a lotiform flower (the Pangaean rose?), and a disk sometimes floral, sometimes solar. But though the appearance of either of these two symbols on a coin suggests at once that it may have been struck in Macedonia, it is by no means conclusive evidence ; for instance there is a typical 'Pangaean' rose as symbol on an archaic coin of Larissa in Thessaly (B.M.C. No. 6) and an equally typical disk symbol on a coin of Idalium with the type of the sphinx (B.M.C. $2-4$ ). So typical indeed is the latter that M. Svoronos apparently regards the coin as Macedonian (see his Pl. XVII. 13), but its Cypriote origin is beyond dispute as apart from questions of type and fabric all the three coins of this class in the B.M. were found at Dali itself. The general method adopted is interesting, but should also be handled with far more caution than is here employed. The author supposes that the boundaries of the prefectures into which the country was divided under Turkish rule, drawn as they were along physical and economic lines, are traditional, and outline what must always have been local units inhabited by tribes or tribal groups. He then takes such coins as bear ethnic inscriptions and with provenance as a pointer, eked out by the scanty literary evidence, he searches the map for a modern place name which may conceal the classical ethnic. Thus the Derrones are located (probably with justice) near Lake Doiran, the Tynteni near Tsintsos and so on. With two or three points thus fixed to his satisfaction the rest follows easily-the more so perhaps as the bulk of the coinage is uninscribed. Arguing in turn from analogy of type, symbol and weight standard, he distributes the remaining coins among tribes whose location he attempts with more or less success. We may admire the dexterity with which the juggler keeps so many balls in the air at the same time and his address in throwing up another to distract our attention directly one falls to the ground, but there the matter ends as regards the majority of the attributions. The cautious numismatist must still be content to class the bulk of these coins under the vaguer title of Thraco-Macedonian. Incidentally, however, many interesting points are raised of which only a few can be taken here. The attribution of the hitherto uncertain coins with the sphinx type and legend $A \Sigma$. . to Assorus is tempting and will probably find acceptance : it is a curious coincidence that there was an important cult of Artemis at Assorus just as there was at Perge, one of the very few other places which used the sphinx type. The octadrachms of the Derronian group with Pegasus for reverse type and a legend hitherto regarded as blundered, are ascribed with considerable likelihood to the Laeaei, a tribe mentioned by Thucydides, and the didrachms with the goat type hitherto attributed on insufficient grounds to A egae are attributed to the same group on the strength of the monograms $\triangle E$ (Derrones) and $\Lambda A$ (Laeaei). The latter attribution is, however, not without difficulty, for the goat-type coins of the Laeaei, although without reverse type and therefore earlier, are of better style than their octadrachms. M. Svoronos holds that there was no regal Macedonian coinage before Alexander I. and assumes (which is more doubtful) that the kings allowed no city of theirs to exercise a right which they did not use themselves. We have seen how he deals with the coins formerly given to Aegae, but he has also to find a new home for those bearing the ethnic IXNAION hitherto assigned to that Ichnae on the Thermaic Gulf. Now Stephanus mentions an Ichnae in Eastern Macedonia and the author assigns the coins in question to this city, which he locates at Zichna ('s "I I $\chi^{\nu a s)}$, east of the Strymon, justlyi remarking that both the types and the high weight of the coins find their closest analogies in the coins of the neighbouring Edones and Orrescii. Before leaving the first part it may be remarked that the legend of the coins with the sow and boar types (PI. XVI. 43 and 50), on strength of which these 
pieces have been assigned to Methone, is in the one case highly problematic and in the other non-existent, and that the attribution to Siris of the series with the type of the horse-Silenus and nymph, formerly given to Lete, breaks down for a similar reason, for while their legend, whatever it may be, does not look like $\Lambda E T A I O I$, still less does it resemble EIPINON.

The same general criticism applies when $\mathbf{M}$. Svoronos in his second part attacks the question-Are there early gold or electrum coins assignable to Macedonia ? He makes such large claims that in pure irritation we are apt to negative them all. His view that the electrum coinage currently assigned to the Ionian revolt was in reality struck in the districts round Myreinus under Milesian influence has already been dealt with in a review by Mr. Hill in the Numismatic Chronicle $(1919, p .313)$ and need not be further discussed here except to say that the provenance of the coins is overwhelmingly Ionian. Some of the other attributions, however, require more serious consideration. There are three lines of argument that may be followed, the argument from style and fabric, from type and from provenance. The first and especially the question of fabric is here ignored; all the certain Thraco-Macedonian silver coins without reverse type have a shallow incuse square set in a noticeably flat field, the majority of electrum coins on the contrary have a comparatively deep incuse in a rough field, and the other evidence would have to be very strong before we could accept a common place of origin for two such different fabrics. There are, however, certain electrum coins with a flat reverse fabric and some of these may well be Macedonian. For example, the stater at Munich with the griffin's head type and the hitherto unexplained inscription IIOE (here PI. XV.1), formerly given to Teos, is connected by M. Svoronos with the heavy pieces of the griffin type (already recognised by von Fritze as not belonging to Abdera) and temptingly assigned to the Dii. Again the type of the electrum coins with the goose and lizard is so exceptional that it is almost impossible to separate it from the silver Thraco-Macedonian coins of the same type and their provenance seems generally Macedonian. The same may be said of the electrum pieces with the curious type of the quartered cube (here explained as an ingot) and in so far the claim that they are Macedonian may be provisionally accepted. Provenance indeed must in the end be the chief argument in such attributions if only sufficient evidence is fortheoming, and it may therefore be worth while to give the results of an examination from this point of view of some of the coins in the British Museum assigned by M. Svoronos to Macedonia. Of eight examples of the pieces with the solar disk in various forms (here Pl. XVI. 6-8, 25 etc.) two are known to have been found in Asia Minor, one was brought from Smyrna, two came with parcels of other coins from Asia Minor, two came from collections formed mainly in Smyrna, while the provenance of the remaining one is quite uncertain. They therefore seem to be Asiatic, though as far as fabric goes some of them might be Macedonian. The electrum staters with the gorgoneion type are brought by $\mathrm{M}$. Svoronos into connexion with the silver coins usually given to Neapolis Datenon, but of the two examples known, that in the Waddington Collection was found in the Dardanelles and the other came to the British Museum in a parcel of other Asiatic coins. Apart from this the electrum pieces have a reverse type which the silver have not, and their styles are quite different. Again, of the two pieces with the Pegasus type (PI. XV. 26) the one whose provenance is known came direct from Smyrna, and in any case the fabric seems typically Asiatic. To proceed would be to turn a review into an article, but enough has been said to indicate that while $\mathbf{M}$. Svoronos' exuberance should be heavily discounted it should not blind us to the suggestiveness of many of his conclusions and in particular to the case he makes against those who would assign all electrum coinage without exception to Asia Minor. 